\title{
Ethical Challenges in the Practice of Remote Sensing and Geophysical Archaeology
}

\author{
Dylan S. Davis ${ }^{1 *}$ and Matthew C. Sanger ${ }^{2 *}$
}

1. Department of Anthropology, The Pennsylvania State University, Pennsylvania, USA

2. National Museum of the American Indian, Smithsonian Institution, Washington D.C., USA

* Correspondence Details: $\underline{\text { dsd40@ } @ \text { psu.edu }}$ (DSD); sangerm@si.edu (MCS)

\section{Introduction}

Within archaeology, concern over ethics has become a center point of debate, particularly in terms of cultural patrimony, repatriation, intellectual property rights, and the display of sensitive items (Conkey \& Gero, 1997; Fabian, 2010; Lynott, 1997; Ortner, 2016; Richardson, 2018; Scarre \& Scarre, 2006; Scheper-Hughes, 1995). Most of these debates center around objects, information, and narratives acquired and built through archaeological excavations and antiquarian collections, while far less attention has been paid to projects that rely on remote sensing technologies (some early exceptions include Myers, 2010; Ur, 2006). Remote sensing technologies are typically viewed as non-destructive, non-invasive, and resulting in non-sensitive data (Sanger \& Barnett 2021). As such, the ability to record objects remotely, be that from space, the air, or the ground, has resulted in a massive expansion of archaeological data over the past several decades, and the use of these techniques has grown considerably since the turn of the $21^{\text {st }}$ century (Boellstorff $\&$ Maurer, 2015; Cooper \& Green, 2016; Huggett, 2020; Luo et al., 2019). With this massive expansion in use, researchers are increasingly considering the broader social, political, economic, and cultural ramifications of using remote sensing technologies and therefore, how they can best be deployed in an ethical manner.

Despite a recent increase in studies highlighting the ethical dilemmas within archaeological remote sensing (e.g., Chase, Chase, \& Chase, 2020; Cohen, Klassen, \& Evans, 2020; Davis, 2020; Fernandez-Diaz \& Cohen, 2020; Fernandez-Diaz et al., 2018; Gupta et al., 2020; Rączkowski, 2020; Sanger \& Barnett, 2021), the conversation on this topic is still underwhelming (see Tables 1 and 2 below). For this reason, among many others, we felt that a formalized discussion of these ethical issues was overdue. In what follows, we will present several major themes of the articles contained in this special issue. Next, we will synthesize the articles contained in this issue. Finally, we will discuss some future goals for remote sensing and geophysical archaeology, particularly detailing what we see as necessary steps for the subdiscipline as it matures and takes its ethical responsibilities seriously.

Full citation: Davis, D. S., \& Sanger, M. C. (2021). Ethical Challenges in the Practice of Remote Sensing and Geophysical Archaeology. Archaeological Prospection. 28(3). https://doi.org/10.1002/arp.1837. This article is published in final form at https://doi.org/10.1002/arp.1837. This article may be used for noncommercial purposes in accordance with Wiley Terms and Conditions for Use of Self-Archived Versions. 


\section{Ethics, Remote Sensing, and Archaeology}

While ethics has been a major topic within archaeology for decades, it is rarely considered when conducting remote sensing studies. According to a Web of Science literature search conducted at the beginning of 2021, there were 269 articles matching the topics of "ethics" and "archaeology". However, when searching for literature focusing on "ethics", "archaeology", and "remote sensing", the number of results was reduced to a resounding 4 articles, none of which appear before 2010 (Table 1). A keyword search in SCOPUS reveals a similar pattern, indicating that publications focused on ethics and remote sensing archaeology are extremely limited (Table 2). The rate of publications focusing on ethics and archaeological use of remote sensing can be contrasted with more "traditional" archaeological techniques (Tables 3 and 4).

Table 1: Search Results in Web of Science (as of January 11, 2021).

\begin{tabular}{|l|l|}
\hline Keyword Search Terms & Number of Results \\
\hline TS=Ethics AND TS=Archaeology & 269 \\
\hline TS=Ethics AND TS=remote sensing AND TS=Archaeology & 4 \\
\hline
\end{tabular}

Note: TS refers to "topic" in the Web of Science search engine.

Table 2: Search Results in SCOPUS (as of January 11, 2021).

\begin{tabular}{|l|l|}
\hline Keyword Search Terms & Number of Results \\
\hline KEY ( "archaeology" ) AND KEY ( "ethics" ) & 154 \\
\hline $\begin{array}{l}\text { KEY ( "archaeology" ) AND KEY ( "remote sensing" ) } \\
\text { AND KEY ( "ethics" ) }\end{array}$ & 5 \\
\hline
\end{tabular}

Note: KEY refers to key terms (or keywords) within the SCOPUS search engine.

These results indicate that while ethics are frequently discussed in archaeological literature, in general, the discussion of these issues within geophysical archaeology has been exceedingly low. This is in line with other recent attempts to quantify explicit mentions of ethics within the context of "digital archaeology" (Dennis, 2020; Richardson, 2018) which is further reinforced in Table 3, demonstrating a clear divide between the discussion of ethics within "traditional" archaeological practices (e.g., excavation, fieldwork, and lab-analysis) and "digital" approaches (e.g., GIS, remote sensing, etc.).

Table 3: Search results from Web of Science (as of January 11, 2021). "Digital" practices are highlighted in green, while "traditional" practices are highlighted in blue. There is a clear distinction between discussions surrounding ethics and these two categories of archaeological research.

\begin{tabular}{|l|l|}
\hline Keyword Search Terms & Number of Results \\
\hline TS=Ethics AND TS=remote sensing AND TS=Archaeology & 4 \\
\hline TS=Ethics AND TS=geophysics AND TS=Archaeology & 0 \\
\hline TS=Ethics AND TS=digital AND TS=Archaeology & 11 \\
\hline TS=Ethics AND TS=GIS AND TS=Archaeology & 2 \\
\hline TS=Ethics AND TS=social media AND TS=Archaeology & 5 \\
\hline TS=Ethics AND TS=3D scanning AND TS=Archaeology & 0 \\
\hline
\end{tabular}




\begin{tabular}{|l|l|}
\hline TS=Ethics AND TS=photogrammetry AND TS=Archaeology & 0 \\
\hline TS=Ethics AND TS=excavation AND TS=Archaeology & 15 \\
\hline TS=Ethics AND TS=fieldwork AND TS=Archaeology & 7 \\
\hline TS=Ethics AND TS=repatriation AND TS=Archaeology & 8 \\
\hline TS=Ethics AND TS=museum AND TS=Archaeology & 15 \\
\hline $\begin{array}{l}\text { TS=Ethics AND TS=destructive } \\
\text { analysis AND TS=Archaeology }\end{array}$ & 1 \\
\hline $\begin{array}{l}\text { TS=Ethics AND TS=chemical } \\
\text { analysis AND TS=Archaeology }\end{array}$ & 1 \\
\hline Total Publications (Digital Practices) & $\mathbf{2 2}$ \\
\hline Total Publications (Traditional Practices) & $\mathbf{4 7}$ \\
\hline
\end{tabular}

Table 4: Search results from SCOPUS (as of January 11, 2021). "Digital" practices are highlighted in green, while "traditional" practices are highlighted in blue. The distinction is less pronounced than the Web of Science results.

\begin{tabular}{|l|l|}
\hline Keyword Search Terms & Number of Results \\
\hline $\begin{array}{l}\text { KEY ( "archaeology" ) AND KEY ( "remote sensing" ) } \\
\text { AND KEY ( "ethics" ) }\end{array}$ & 5 \\
\hline $\begin{array}{l}\text { KEY ( "archaeology" ) AND KEY ( "geophysics" ) AND } \\
\text { KEY ( "ethics" ) }\end{array}$ & 0 \\
\hline $\begin{array}{l}\text { KEY ( "archaeology" ) AND KEY ( "digital" ) AND KEY } \\
\text { ( "ethics" ) }\end{array}$ & 5 \\
\hline $\begin{array}{l}\text { KEY ( "archaeology" ) AND KEY ( "GIS" ) AND KEY ( } \\
\text { "ethics" ) }\end{array}$ & 0 \\
\hline $\begin{array}{l}\text { KEY ( "archaeology" ) AND KEY ( "social media" ) AND } \\
\text { KEY ( "ethics" ) }\end{array}$ & 1 \\
\hline $\begin{array}{l}\text { KEY ( "archaeology" ) AND KEY ( "3D scanning" ) AND } \\
\text { KEY ( "ethics" ) }\end{array}$ & 0 \\
\hline $\begin{array}{l}\text { KEY ( "archaeology" ) AND KEY ( "photogrammetry" ) } \\
\text { AND KEY ( "ethics" ) }\end{array}$ & 0 \\
\hline $\begin{array}{l}\text { KEY ( "archaeology" ) AND KEY ( "excavation" ) AND } \\
\text { KEY ( "ethics" ) }\end{array}$ & 2 \\
\hline $\begin{array}{l}\text { KEY ( "archaeology" ) AND KEY ( "fieldwork" ) AND } \\
\text { KEY ( "ethics" ) }\end{array}$ & 1 \\
\hline $\begin{array}{l}\text { KEY ( "archaeology" ) AND KEY ( "repatriation" ) AND } \\
\text { KEY ( "ethics" ) }\end{array}$ & 4 \\
\hline $\begin{array}{l}\text { KEY ( "archaeology" ) AND KEY ( "museum" ) AND } \\
\text { KEY ( "ethics" ) }\end{array}$ & 7 \\
\hline $\begin{array}{l}\text { KEY ( "archaeology" ) AND KEY ( "destructive analysis" ) } \\
\text { AND KEY ( "ethics" ) }\end{array}$ & 0 \\
\hline $\begin{array}{l}\text { KEY ( "archaeology" ) AND KEY ( "chemical analysis" ) } \\
\text { AND KEY ( "ethics" ) }\end{array}$ & 0 \\
\hline
\end{tabular}




\begin{tabular}{|l|l|}
\hline Total Publications (Digital Practices) & 11 \\
\hline Total Publications (Traditional Practices) & 14 \\
\hline
\end{tabular}

We posit that the divergence in ethical considerations found between "traditional" archaeological practices and "digital" techniques is based on two presumptions made by archaeologists. The first is that because digital techniques result in arithmetic data, rather than physical objects, that their products are somehow fundamentally distinct from the material world that they measure (see Blanchette, 2011). Dennis (2020, 212), makes a similar assertion when stating that ethical guidelines within archaeology often fail when applied to "digital" archaeology, not only because of the exclusion of such specific methods within ethical codes, but also because of the transition from "analog to digital tools, paper to virtual methodologies, and the theoretical positioning of the digital as practice, method, or specialization."

Second, because these digital techniques do not require the movement of earth, there is a presupposition among some practitioners that their deployment does not impact local or descendent communities, a point that researchers have begun to question (see Garstki, 2020; Richardson, 2018). In fact, with digital datasets, a wider range of potential negative impacts can befall stakeholders, including the dehumanization of past peoples (and their modern descendants), the claim of open-access of information when such data are rarely accessible to those outside of academia, and a widening distance between local community knowledge and archaeological research (Dennis, 2020; Garstki, 2020; Gupta et al., 2020; Huggett, 2020; Mickel, 2020; Richardson, 2018). These potential pitfalls can be even more plentiful and hazardous when working with Indigenous communities, including Native Americans, as the deployment of digital techniques can feed into stereotypical tropes pitting "science" vs. Natives, while also devaluing traditional knowledge holders and desecrating places that are home to ancestral peoples (Sanger \& Barnett, 2021).

Remote sensing certainly must grapple with all of these issues: by its nature these techniques are non-invasive and so are often utilized without direct collaborations with local communities and stored in ways that are not directly usable (or accessible) without specialized training and software. Davis (2020) highlights imbalances within the applications of AI and remote sensing within archaeological research, illustrating that collaboration between different institutions (and international collaboration, in general) are extremely limited, leaving many scholars (and by extension local communities) from places around the world out of these research initiatives. In addition to geographic divisions in the applications of advanced remote sensing methods, there are other pressing issues with these techniques in general. Among the many issues present in remote sensing research are power dynamics, informed consent, potential dissemination of sensitive information that can result in damage to cultural heritage sites, among others, many of which are touched upon in the articles in this issue (also see Gupta et al., 2020; Myers, 2010; Parcak, 2009).

Although the ethical issues surrounding remote sensing are diverse, we suggest that archaeologists ought to consider several key parameters when using remote sensing technologies if they hope to conduct this work in an ethical manner, which we detail below. 
Methods are always deployed in a broader socio-political context. Understanding the impact of archaeology beyond the boundaries of academic discourse has been crucial in the maturation of our discipline from antiquitarian collecting to our current state of debate about how to best serve contemporary communities, work with Indigenous groups, and rewrite broader nationalistic, imperialistic, and racist narratives of the past (e.g., Deloria, 1969; Gallivan et al., 2011; Gosden, 2006; Kohl, 1998; Lewis, 1998; Salzman, 2002). While most, if not all, archaeologists appreciate the ways in which traditional archaeological practices must be deployed with care (gone are the days of unbridled excavations and destructive analyses regardless of constituency concerns) far fewer appreciate how remote data acquisition methods are also enmeshed within broader sociopolitical power structures. As such, it is critical that researchers consider the broader ramifications of their work when planning, implementing, and reporting their studies. For example, Johnson et al. (this issue), highlight how remote sensing data - particularly that which is funded through governmental or public funds - requires careful consideration regarding its availability and accessibility by local stakeholders and subsequent protection by archaeologists. Outreach initiatives are suggested as a means by which to improve protection efforts with the help of local communities (also see Fisher et al., this issue; Lim et al., this issue). Davis et al. (this issue) also discuss how the use of remote sensing can bypass local laws and customs pertaining to site access and visitation rights, and thus the use of these methods should always be in consultation with local community leaders to ensure cultural values are not violated (also see Lim et al., this issue).

Remote sensing technologies can create, maintain, or strengthen asymmetrical power relationships. A central concern of any ethical research project (archaeological or not) is whether it will have negative effects on already marginalized, persecuted, dispossessed, or dominated groups. As papers in this issue outline (e.g., Davis et al., this issue; Johnson et al., this issue; Lim et al., this issue; Wadsworth et al., this issue), remote sensing projects are often deployed by centralized power holders (whether governmental, organizational, or academic) to study the histories of racial/ethnic minorities (especially Indigenous peoples), economically disadvantaged groups, or otherwise less empowered communities. As such, archaeologists need to consider how their access to remote sensing technologies and data often emerges from already pre-existing power imbalances and the ways in which their work can be complicit in the maintenance of these power structures.

These considerations can seem unnecessary as remote sensing often appears to have little direct impact on local communities who may not even realize such work has occurred. In this manner, remote sensing is akin to surveillance, a topic now undergoing its own ethical reformulation as researchers have largely come to the conclusion that data acquisition often requires some level of consent even when it could be conducted without the knowledge of the surveilled individual (Davis et al., this issue; Myers, 2010; Rączkowski, 2020). This leads to ethical quandaries concerning informed consent when conducting remote sensing projects, as the natures of these technologies are not common knowledge among all people. Given the unfamiliarity of how satellites and drones (among other geophysical instruments) operate, can local stakeholder communities truly provide consent for the recording of information by means that they do not fully understand?

One solution to this particular ethical concern stems from education and outreach initiatives (e.g., Cohen et al., 2020; Davis, 2020; Fisher et al., this issue; Johnson et al., this issue) and ensuring 
local communities are involved in research at all stages (from planning and data acquisition to publication). This includes incorporating local (emic) perspectives into research design and data analysis, as Monteleone et al. (this issue) demonstrate using a "processual-plus" theoretical framework combining phenomenological and evolutionary perspectives. It is not enough to ask permission to record information, but a mutual understanding of how different technologies operate is required for full consent to be achieved between researchers and local communities.

The nature of remote sensing data creates unique ethical considerations. Remote sensing data, often made up of pixels, data points, and other digital information, can appear benign and unproblematic, yet contains and creates its own sets of ethical challenges. The ability to analyze and interpret remote sensing data typically relies on highly specialized knowledge and software. As such, remote sensing data can create a divide between experts and non-experts in ways that physical objects do not. Indeed, discussions between archaeologists and local enthusiasts are often strengthened by the presence of a stone tool or ceramic sherd - rarely do similar conversations emerge when looking at radar data.

Because remote sensing data appears benign and are digital in form, they are often shared widely. Archaeologists understand that the widescale dissemination of remote sensing data needs to be limited by concerns over revealing the precise location of an archaeological site as this creates opportunities for looting and vandalism (e.g., Parcak, 2009; Johnson et al., this issue), but we less commonly question whether we should be sharing the data at all, even when obscuring exactly where it came from. Fisher et al. (this issue) summarize a major component of this problem by posing the question: "is it ethically sound to move directly from open-access geographic facts to open-data archaeological interpretation?" In other words, is it fair for researchers to dictate to local communities who can access information pertaining to their ancestors and history (also see Cohen et al., 2020)? Certainly in the case of privately funded data acquisition there is an argument for who "owns" those data, but there is also an argument for "moral ownership", wherein people or institutions with special interests or ownership of the entities captured by remotely sensed datasets, should be granted access and perhaps control in addition to or perhaps in preference to the proprietors of that information (Fernandez-Diaz \& Cohen, 2020).

Narratives created using remote sensing data can create unique conflicts. Often acquired at massive scales and resulting in equally massive datasets, narratives built on remote sensing technologies can be given extraordinary weight and can attest to large-scale archaeological questions regarding landscape modification, group mobility, land ownership, and other topics that are very important to local communities. Because of their importance, many of these topics have already been addressed by local traditional knowledge holders. As such, narratives built on remote sensing technologies can come into conflict with local histories in ways similar to narratives built on other archaeological methods (such as broad-scale terrestrial survey or GIS-based analyses of excavation or analytical datasets).

The nature of remote sensing data can create unique sorts of conflicts as they often rely on datasets that appear more objective, scientific, and unimpeachable than datasets achieved using more traditional archaeological techniques. While archaeologists often want to "ground-truth" anomalies, patterns, and other findings within remote sensing data, there is broad understanding 
of remote sensing technologies as powerful tools capable of discovering otherwise imperceptible archaeological phenomena. Because remote sensing produces broad and multifaceted datasets, archaeologists need to be particularly careful when they result in narratives that conflict with traditional knowledge holders.

Much like narratives built using other archaeological methods are increasingly including traditional knowledge in their interpretations, archaeologists deploying remote sensing ought to strive to include local ways of knowing and local histories when developing their own conclusions as a means of reducing conflict with local communities (e.g., Lim et al., this issue; Monteleone et al. this issue). This is particularly important when studying sites and phenomena that are especially culturally sensitive. Non-invasive methods like remote sensing and geophysical investigation are imperative for working in regions where direct disturbance is prohibited. In addition, the use of non-invasive methods can be used to establish trust between researchers and stakeholders - key to ethical investigations - and pave the way for additional projects conducted in concert with local communities (see Sanchez et al., 2021). As is argued in this special issue (e.g., Davis et al., this issue), the recording of any information in such high-sensitivity areas should be considered off limits prior to obtaining consent from local indigenous or other stakeholder communities. A government permit should not be considered adequate, as such documents may not involve direct consultation with local communities (see Gupta et al., 2020).

\section{Goals of this special issue and future of archaeological remote sensing}

This special issue of Archaeological Prospection attempts to advance conversations around important topics pertaining to ethical practices for archaeological geophysics. Specifically, the papers in this issue address topics ranging from data sharing and availability, community engagement, respect for cultural taboos and values, surveillance and property rights, and remote sensing's impact on local communities.

While negative implications and challenges of remote sensing applications are discussed, the issue also highlights potential solutions to these issues and positive outcomes that can result from archaeological remote sensing. For example, investigating previously understudied regions and documenting at-risk and disappearing cultural heritage, while filled with ethical quandaries, can be exceedingly beneficial for protecting and preserving local histories and traditional knowledge (Fisher et al., this issue; Johnson et al., this issue; Lim et al., this issue; Linares-Matás \& Lim, this issue; Wadsworth et al., this issue). Collaborative remote sensing archaeological studies can also address pivotal archaeological questions that are important to both academic researchers and local communities (Cody \& Anderson, 2021; Davis et al., this issue; Lim et al., this issue; Monteleone et al., this issue; Nelson, 2021; Warrick et al., 2021). Finally, remote sensing can be used as a means of engaging local community members and conducting non-invasive research in areas of high cultural sensitivity (e.g., Davis et al., this issue; Linares-Matás \& Lim, this issue; Wadsworth et al., this issue, 2021). In particular, the inclusion of training programs as part of remote sensing research can alleviate major barriers present in some regions where knowledge of such technologies by local communities are limited (Davis et al., this issue; Fisher et al., this issue).

In what follows, we introduce the articles included in this special issue. These papers provide insights from a multitude of scholars and cover a broad range of geographies, topics, and 
perspectives. Ultimately, they all align in their focus on directly confronting the potential implications of advancing technological methods in our discipline. These articles are, therefore, an important set of references for the development of ethical guidelines for geophysical archaeological practice and scholarship.

\section{Synopsis of the Special Issue Papers}

This special issue consists of a total of 7 articles submitted from scholars around the world, including case studies from North America, Africa, and Asia. While geographic coverage is far from complete, the themes across these papers are very much congruous, indicating that the issues and dilemmas faced among scholars around the world are in many ways transferrable regardless of geographic focus.

Michael Fisher and colleagues investigate the reason for a lack of discussion of archaeological ethics pertaining to remote sensing research. They use the Endangered Archaeology in the Middle East and North Africa (EAMENA) project (Bewley et al., 2016) as a case study and evaluate the progress of the longstanding research venture, paying particular attention to the lack of formalized consideration on the ethical uses of remote sensing technologies for cultural preservation efforts. Rather than advocate for specific codified ethical guidelines, Fisher and colleagues explore a different approach based on humanitarian goals, which they argue allows for specifically designed frameworks for international projects where power relationships may be asymmetrical. Central to these humanitarian goals are concepts of respect, accountability, knowledge-sharing, sustainability, and empowerment, among others. Pointing to a similar notion of power imbalances discussed by others in this issue (e.g., Davis et al. this issue), Fisher and colleagues advocate for research programs that offer training opportunities to communities in regions where knowledge of remote sensing is limited to ensure that the opinions and ideas of local communities are incorporated into all studies employing such geospatial information.

The importance of education initiatives is also considered by Katherine Johnson and colleagues, who highlight the issues surrounding open access lidar datasets using a case study from the Northeastern United States. They emphasize that the availability of large-scale, high-resolution datasets (specifically lidar data) offer unparalleled advantages for archaeologists; but with these advantages comes the potential of disadvantages in the form of looting or damage to cultural heritage sites. As the authors explain, navigating the ethical issues at play within publicly funded (and thus publicly available) lidar data is a tightrope walk between funding agency requirements, taxpayer funded datasets, potential harm to cultural sites, and advantages for archaeologists, tribal governments, and other researchers. One of the suggestions that Johnson and colleagues put forth in their editorial for addressing these potential safety issues for cultural heritage is through public education and outreach (also see Fisher et al. this issue), as improving knowledge about historic places can alleviate disturbance by recreational groups who can (un)intentionally destroy archaeological contexts in areas with easy accessibility. By improving historical knowledge of the general public archaeological research can improve twofold: we can increase our records of archaeological sites and collaborate with local communities to protect these cultural heritage areas.

Next, Dylan Davis et al. provide a case study from Madagascar, where they show how the issue of asymmetric power structures stemming from surveillance can be addressed by archaeologists 
via collaborative research agendas with local communities. In particular, they stress the importance of consulting local communities prior to the analysis of satellite imagery or collection of aerial photography, to ensure that culturally sensitive, taboo, or otherwise "off-limits" areas are not recorded without proper permission. Fisher et al. (this issue) make a similar claim about satellite imagery, which is one form of remote sensing data that does not require any ties to the people or places being surveilled, making them a source of ethical ambiguity if the consultation of local stakeholders is ignored. Ultimately, Davis and colleagues argue that an ethical practice of remote sensing archaeology requires equal participation between researchers and stakeholder communities at all levels of research, ranging from project planning, the generation of datasets, the analysis of data, and how such data will ultimately be used or disseminated. This is particularly vital when culturally sensitive areas are included within a particular project's area of interest and when new datasets (e.g., drone imagery) are being collected.

The importance of collaboration between academic researchers and indigenous communities is further emphasized by William Wadsworth, Kisha Supernant, and Vadim Kravchinsky, who demonstrate how remote sensing technologies can assist indigenous communities in preserving and recording their histories in the Saskatchewan area of Canada. This theme is shared by other contributions in this issue, including Lim et al. (in Alaska) and Monteleone et al. (in Alaska and Mesoamerica). In their paper, Wadsworth and colleagues demonstrate how a multisensory approach can elucidate ephemeral campsites occupied for short periods of time. This capability can provide evidence needed for indigenous communities to gain legal authority over ancestral lands and the ability to protect their own cultural heritage. The central tenet of inclusivity in the scientific process displayed by Wadsworth et al. (also see Wadsworth et al., 2021) is present in many of the articles contained in this issue (e.g., Davis et al., this issue; Fisher et al., this issue; Lim et al., this issue)

Moving further north into Alaska, Jonathan Lim and colleagues demonstrate remote sensing can be applied to archaeological investigations in a collaborative manner rooted in community engagement and traditional ecological knowledge (TEK). The authors develop a research framework that enables remote sensing to be coupled with TEK and other ethnographic and historic information to enhance interpretations of the archaeological record, improve preservation efforts of at-risk archaeological sites, improve the accuracy of machine learning algorithms designed to locate archaeological sites, and promote an equitable archaeological practice that benefits local communities and academics, alike. Similar approaches has been applied elsewhere (e.g., Davis, DiNapoli, \& Douglass, 2020; Verhagen \& Whitley, 2012; also see Lambers et al., 2019), and such engagement with local communities is a central theme of many articles within this special issue (e.g., Davis et al. this issue; Monteleone et al. this issue; Wadsworth et al. this issue). Lim and colleagues ultimately demonstrate the power of local engagement - and ethnographic research in particular - with respect to remote sensing archaeology, as local knowledge and perspectives permit for improved methods for archaeological prospection as well as the ability for local communities to increase their authority over their cultural heritage (also see Cody \& Anderson, 2021; Fisher et al., this issue; Wadsworth et al., 2021, this issue).

Ensuring that proper permissions are granted by stakeholder communities to researchers studying significant cultural sites is a longstanding issue around the world, as many indigenous communities 
still struggle in maintaining autonomy over their cultural heritage (e.g., Cohen et al., 2020; Gupta et al., 2020). This is an important consideration in any research project, but even more so in sensitive cultural contexts (e.g., taboo areas, holy sites, burials, sites of mass violence, etc. [e.g., Davis et al. this issue; Sturdy Colls, 2015]). Gonzalo Linares-Matás and Jonathan Lim delve into remote sensing applications in West Africa for locating funerary architecture. Many such locales are considered sacred by local communities and are of the highest order of cultural significance (Stone \& Stirling, 2007). Utilizing semi-automated image analysis methods, the authors document the distributional pattern of funerary architecture and settlements within Dhar Tagant, Mauritania. Reiterating many of the themes present throughout the articles in this special issue, Linares-Matás and Lim argue that remote sensing archaeological studies - especially those focused on landscape features as culturally significant as funerary monuments - require "collaborative conversation" with local descendent communities. Importantly, Linares-Matás and Lim emphasize that remote sensing technologies provide the ability for archaeologists to challenge stereotypes of African societies by highlighting important innovations in resource management strategies. The authors also highlight the use of accessible, open-source software that promotes data sharing to assist in heritage protection and planning efforts (also see Beck \& Neylon, 2012; Marwick, 2017; Wilson et al., 2020).

After the collection of geophysical data, the interpretation of such information can be a difficult task with significant implications. Kelly Monteleone, Amy Thompson, and Keith Prufer discuss how interpretations of remote sensing studies can impact cultural resource management using case studies from Alaska and Mesoamerica. In discussing how remotely sensed information should be treated with respect to interpreting the archaeological record, the authors argue that ultimately such use should involve local knowledge and perspectives, and approach this using a combination of phenomenological and human behavioral ecological perspectives. This theoretical union allows for the creation of "virtual cultural landscapes", which permit for the revisitation of places long since lost to the sands of time, or those that are hidden and difficult to access in person. Additionally, this approach allows the authors to understand the how and why of past human actions. Monteleone and colleagues argue that remote sensing technologies can provide an effective means to reconstruct and understand past human interactions with landscapes.

\section{Conclusions}

The applications of remote sensing and geophysical instruments in archaeology have expanded rapidly in recent decades. With the explosion in new methodological and research applications of these technologies, a reflection on the part of researchers is needed on the ethical issues that may result from their use. Among the many dilemmas with which researchers must grapple include: 1) informed consent and inclusivity; 2) data stewardship and privacy; 3) education and outreach; and 4) best practices for geophysical investigations in areas of high cultural sensitivity. These four components are certainly not all-encompassing, but rather consist of a starting set of principles that all researchers should be aware of prior to the start of any research program. Ultimately, researchers should strive to establish strong relationships with local communities to ensure that all 
voices are incorporated into research projects and, by extension, all results are disseminated equally between all involved parties (Wadsworth et al., 2021).

The collection of articles presented in this special issue seek to advance professional conversations among archaeologists that challenge how we practice geophysical archaeology. Fisher et al. (this issue) echo an important sentiment of this special issue when they emphasize that the number of archaeological remote sensing projects has risen exponentially, as has the amount of digital data, presenting a significant need for researchers to face ethical concerns related to these datasets. Ethical codes and standards are central to modern archaeological practice, and yet the methods employed by remote sensing specialists within this field are often absent from such professional guidelines (see Dennis, 2020; also see Davis et al., this issue). These methods are becoming commonplace within archaeology, and therefore require ethical standards to ensure they are used appropriately. As such, we hope that the discussions offered by this special issue will serve as a set of guidelines for future remote sensing archaeology to ensure that such research is conducted in an ethical and responsible manner.

\section{Acknowledgements}

We wish to thank the executive editors, Drs. Eileen Ernenwein and Grigoris Tsokas, for supporting this special issue of Archaeological Prospection. We also wish to express our thanks to all the authors and reviewers of the articles who made this special issue possible.

Data Availability Statement: Data sharing not applicable to this article as no datasets were generated or analyzed during the current study.

Conflict of Interest Statement: The authors have no conflicts of interest to declare.

\section{References}

Beck, A., \& Neylon, C. (2012). A vision for Open Archaeology. World Archaeology, 44(4), 479-497. https://doi.org/10.1080/00438243.2012.737581

Bewley, R., Wilson, A., Kennedy, D., Mattingly, D., Banks, R., Bishop, M., Bradbury, J., Cunliffe, E., Fradley, M., \& Jennings, R. (2016). Endangered archaeology in the Middle East and North Africa: Introducing the EAMENA project. CAA2015. Keep the Revolution Going: Proceedings of the 43rd Annual Conference on Computer Applications and Quantitative Methods in Archaeology, 1, 919.

Blanchette, J.-F. (2011). A material history of bits. Journal of the American Society for Information Science and Technology, 62(6), 1042-1057. https://doi.org/10.1002/asi.21542

Boellstorff, T., \& Maurer, B. (Eds.). (2015). Data, Now Bigger and Better. Prickly Paradigm Press.

Chase, A. S. Z., Chase, D., \& Chase, A. (2020). Ethics, New Colonialism, and Lidar Data: A Decade of Lidar in Maya Archaeology. Journal of Computer Applications in Archaeology, 3(1), 51-62. https://doi.org/10.5334/jcaa.43

Cody, T. R., \& Anderson, S. L. (2021). LiDAR predictive modeling of Pacific Northwest mound sites: A study of Willamette Valley Kalapuya Mounds, Oregon (USA). Journal of Archaeological Science: Reports, 38, 103008. https://doi.org/10.1016/j.jasrep.2021.103008 
Cohen, A., Klassen, S., \& Evans, D. (2020). Ethics in Archaeological Lidar. Journal of Computer Applications in Archaeology, 3(1), 76-91.

Conkey, M. W., \& Gero, J. M. (1997). Programme to Practice: Gender and Feminism in Archaeology. Annual Review of Anthropology, 26, 411-437.

Cooper, A., \& Green, C. (2016). Embracing the Complexities of 'Big Data' in Archaeology: The Case of the English Landscape and Identities Project. Journal of Archaeological Method and Theory, 23(1), 271-304. https://doi.org/10.1007/s10816-015-9240-4

Davis, D. S. (2020). Geographic disparity in machine intelligence approaches for archaeological remote sensing research. Remote Sensing, 12(1), 921. https://doi.org/10.3390/rs12060921

Davis, D. S., DiNapoli, R. J., \& Douglass, K. (2020). Integrating point process models, evolutionary ecology, and traditional knowledge improves landscape archaeology: A case from Southwest Madagascar. Geosciences, 10(8), 267. https://doi.org/10.3390/geosciences10080287

Deloria, V. (1969). Custer Died for Your Sins. Macmillan Press.

Dennis, L. M. (2020). Digital Archaeological Ethics: Successes and Failures in Disciplinary Attention. Journal of Computer Applications in Archaeology, 3(1), 210-218. https://doi.org/10.5334/jcaa.24

Fabian, A. (2010). The Skull Collectors: Race, Science, and America's Unburied Dead. University of Chicago Press.

Fernandez-Diaz, Juan C., \& Cohen, A. S. (2020). Whose Data Is It Anyway? Lessons in Data Management and Sharing from Resurrecting and Repurposing Lidar Data for Archaeology Research in Honduras. Journal of Computer Applications in Archaeology, $3(1)$.

Fernandez-Diaz, Juan Carlos, Cohen, A. S., González, A. M., \& Fisher, C. T. (2018). Shifting perspectives and ethical concerns in the era of remote sensing technologies. SAArchaeological Record, 18(2), 8-15.

Gallivan, M., Moretti-Langholtz, D., \& Woodard, B. (2011). Collaborative archaeology and strategic essentialism: Native empowerment in Tidewater Virginia. Historical Archaeology, 45(1), 10-23.

Garstki, K. (2020). Digital Innovations in European Archaeology (1st ed.). Cambridge University Press. https://doi.org/10.1017/9781108881425

Gosden, C. (2006). Race and racism in archaeology: Introduction. World Archaeology, 38(1), 17.

Gupta, N., Blair, S., \& Nicholas, R. (2020). What We See, What We Don't See: Data Governance, Archaeological Spatial Databases and the Rights of Indigenous Peoples in an Age of Big Data. Journal of Field Archaeology, 45(sup1), S39-S50. https://doi.org/10.1080/00934690.2020.1713969

Huggett, J. (2020). Is Big Digital Data Different? Towards a New Archaeological Paradigm. Journal of Field Archaeology, 45(sup1), S8-S17. https://doi.org/10.1080/00934690.2020.1713281

Kohl, P. L. (1998). Nationalism and Archaeology: On the Constructions of Nations and the Reconstructions of the Remote Past. Annual Review of Anthropology, 27, 223-246.

Lambers, K., Verschoof-van der Vaart, W., \& Bourgeois, Q. (2019). Integrating Remote Sensing, Machine Learning, and Citizen Science in Dutch Archaeological Prospection. Remote Sensing, 11(7), 794. https://doi.org/10.3390/rs11070794 
Lewis, H. S. (1998). The Misrepresentation of Anthropology and Its Consequences. American Anthropologist, 100(3), 716-731.

Luo, L., Wang, X., Guo, H., Lasaponara, R., Zong, X., Masini, N., Wang, G., Shi, P., Khatteli, H., Chen, F., Tariq, S., Shao, J., Bachagha, N., Yang, R., \& Yao, Y. (2019). Airborne and spaceborne remote sensing for archaeological and cultural heritage applications: A review of the century (1907-2017). Remote Sensing of Environment, 232, 111280. https://doi.org/10.1016/j.rse.2019.111280

Lynott, M. J. (1997). Ethical principles and archaeological practice: Development of an ethics policy. American Antiquity, 589-599.

Marwick, B. (2017). Computational Reproducibility in Archaeological Research: Basic Principles and a Case Study of Their Implementation. Journal of Archaeological Method and Theory, 24(2), 424-450. https://doi.org/10.1007/s10816-015-9272-9

Mickel, A. (2020). The Proximity of Communities to the Expanse of Big Data. Journal of Field Archaeology, 45(sup1), S51-S60. https://doi.org/10.1080/00934690.2020.1713284

Myers, A. (2010). Camp Delta, Google Earth and the ethics of remote sensing in archaeology. World Archaeology, 42(3), 455-467. https://doi.org/10.1080/00438243.2010.498640

Nelson, P. (2021). The Role of Low Impact and Geophysical Technologies in Collaborative and Co-Constituted Archaeological Practice with Tribes in Central California. Advances in Archaeological Practice. In Press.

Ortner, S. B. (2016). Dark anthropology and its others: Theory since the eighties. Hau: Journal of Ethnographic Theory, 6(1), 47-73.

Parcak, S. H. (2009). Satellite Remote Sensing for Archaeology. Routledge.

Rączkowski, W. (2020). Power and/or Penury of Visualizations: Some Thoughts on Remote Sensing Data and Products in Archaeology. Remote Sensing, 12(18), 2996. https://doi.org/10.3390/rs12182996

Richardson, L.-J. (2018). Ethical challenges in digital public archaeology. Journal of Computer Applications in Archaeology, 1(1), 64-73.

Salzman, P. C. (2002). On Reflexivity. American Anthropologist, 104(3), 805-813.

Sanchez, G. M., Grone, M. A., Apodaca, A. J., Byram, R. S., Lopez, V., \& Jewett, R. A. (2021). Sensing the Past: Perspectives on Collaborative Archaeology and Ground Penetrating Radar Techniques from Coastal California. Remote Sensing, 13(2), 285.

Sanger, M., \& K. Barnett. 2021. Remote Sensing and Indigenous Communities: Challenges and Opportunities. Advances in Archaeological Practice. In Press.

Scarre, C., \& Scarre, G. (2006). The ethics of archaeology: Philosophical perspectives on archaeological practice. Cambridge University Press.

Scheper-Hughes, N. (1995). The Primacy of the Ethical: Propositions for a Militant Anthropology. Current Anthropology, 36(3), 409-440.

Stone, D. L., \& Stirling, L. (2007). Mortuary Landscapes of North Africa. University of Toronto Press.

Sturdy Colls, C. (2015). Uncovering a painful past: Archaeology and the Holocaust. Conservation and Management of Archaeological Sites, 17(1), 38-55.

Ur, J. (2006). Google Earth and archaeology. The SAA Archaeological Record, 6(3), 35-38.

Verhagen, P., \& Whitley, T. G. (2012). Integrating Archaeological Theory and Predictive Modeling: A Live Report from the Scene. Journal of Archaeological Method and Theory, 19(1), 49-100. https://doi.org/10.1007/s10816-011-9102-7 
Wadsworth, W. T. D., Supernant, K., Dersch, A., \& the Chipewyan Prairie First Nation. (2021). Integrating Remote Sensing and Indigenous Archaeology to Locate Unmarked Graves: A Case Study from Northern Alberta, Canada. Advances in Archaeological Practice, 1-13. https://doi.org/10.1017/aap.2021.9

Warrick, G., Glencross, B., \& Lesage, L. (2021). The Importance of Minimally Invasive Remote Sensing Methods in Huron-Wendat Archaeology. Advances in Archaeological Practice, $1-12$.

Wilson, J. P., Butler, K., Gao, S., Hu, Y., Li, W., \& Wright, D. J. (2020). A Five-Star Guide for Achieving Replicability and Reproducibility When Working with GIS Software and Algorithms. Annals of the American Association of Geographers, 1-7.

https://doi.org/10.1080/24694452.2020.1806026 